$$
\begin{aligned}
& \text { تأثير تغيير الأحمال العضوية وأحمال النتروجين والفسفور في كفاعة إزالة الملوثات }
\end{aligned}
$$

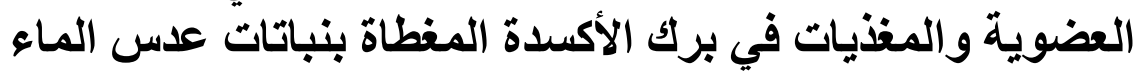

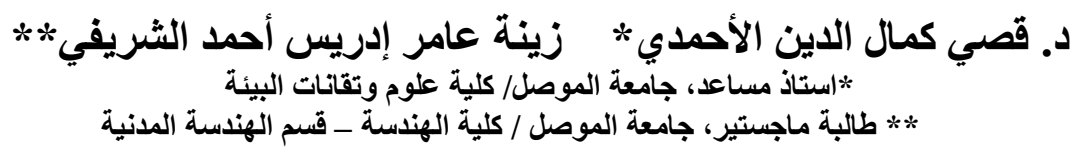

\title{
الخلاصة
}

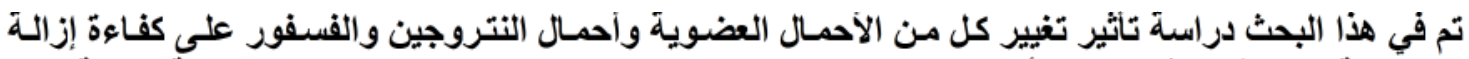

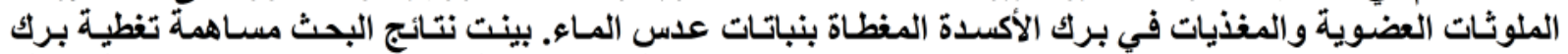

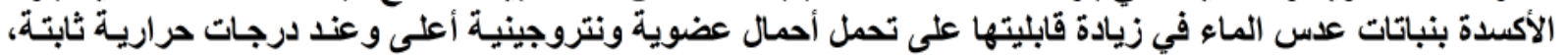

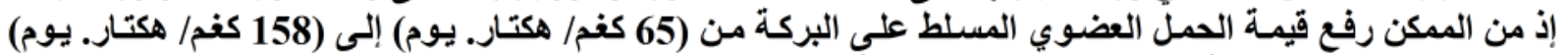

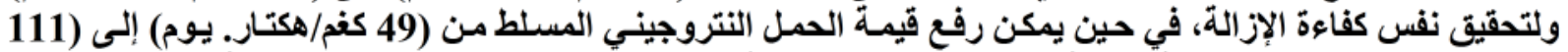

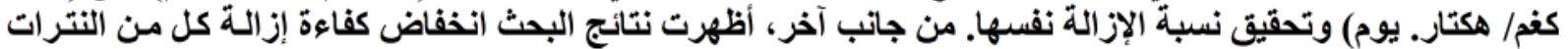

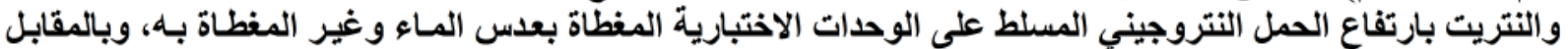

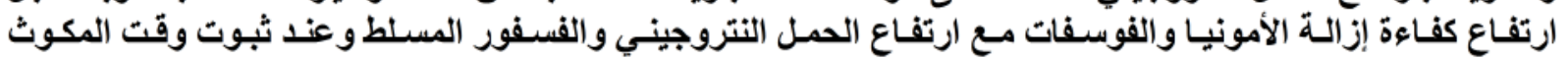
الهيلروليكي لكلا الحالتين.

Keywords: Duckweed; Stabilization ponds; Nutrient removal; Organic load; nitrogen load; phosphorus load

\section{Effect of Organic, Nitrogenous and Phosphorus Loads Variation on the Removal Efficiency of Organic and Nutrients Pollutants In Duckweed Based Wastewater Stabilization Ponds}

\author{
Dr. Kossay K. Al-Ahmady* and Zena A. AL-Shrefy ** \\ * Ass. Professor, University of Mosul, College of Environmental Science and Technology. \\ ** M.Sc, University of Mosul, College of Engineering, Civil Eng. Dept.
}

\begin{abstract}
In this research, an experimental laboratory plant was constructed in order to evaluate the effect of organic, nitrogenous and phosphorus loads on the removal efficiency and behavior of duckweed based wastewater stabilization ponds. The results of the study showed that; covering the oxidation ponds with duckweed improve their ability to treat higher organic and nitrogenous loads. In addition, covering the oxidation ponds with duckweed improve their ability to treat higher organic and nitrogenous loads. Organic and nitrogen load can be increased from $(65 \mathrm{~kg} / \mathrm{ha}$. day $)$ to $(158 \mathrm{~kg} / \mathrm{ha}$. day) and from (49 $\mathrm{kg}$. ha. day) to $(111 \mathrm{~kg} / \mathrm{ha}$. day) by covering the ponds by duckweed. On the other hand, the results of research also showed that; increasing nitrogen and phosphor load leads to decrease removal efficiency of nitrate, nitrite, and increases removal efficiency of ammonia and phosphate at the same hydraulic retention time.
\end{abstract}

$$
\text { قبل: } 2014 \text { - } 30
$$$$
\text { أستلم: } 2013 \text { - } 4 \text { - } 8
$$ 


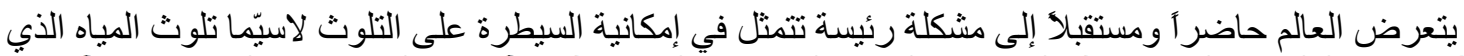

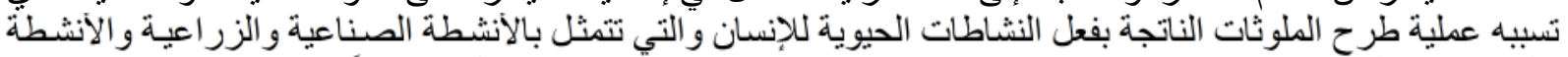

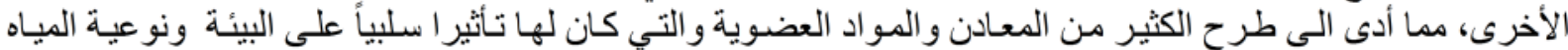
والأنظمـة الإحيائية الموجـودة فيهـا(Thurman \& Webber 1984) ، (GESAMP, 1993) (الناصـري، 1988)

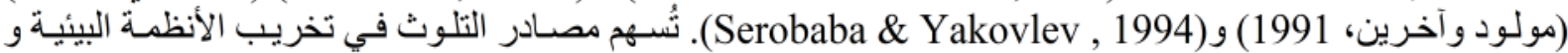

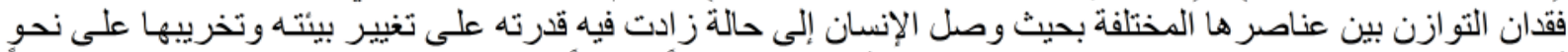

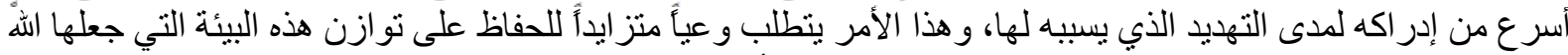

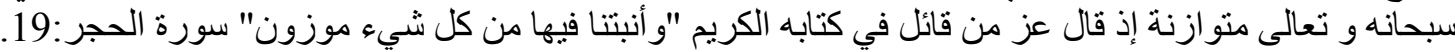

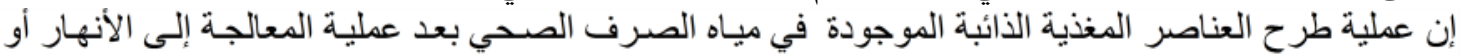

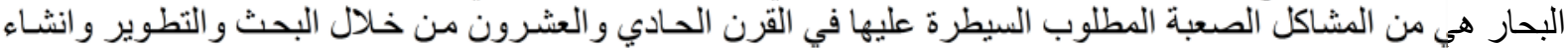
وحدات المعالجة المناسبة (الطائي، 2010).

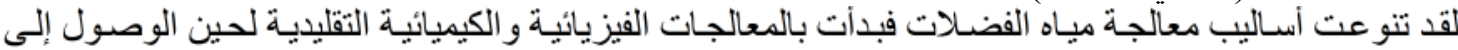

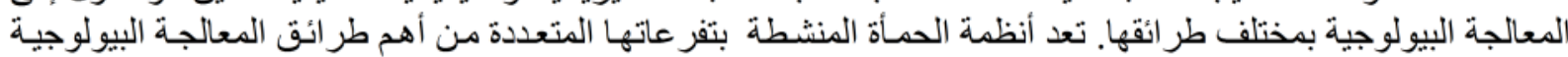

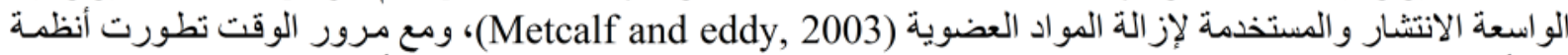

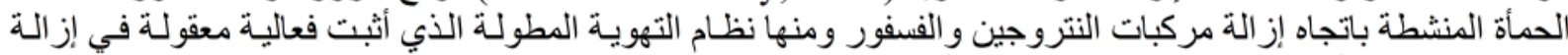

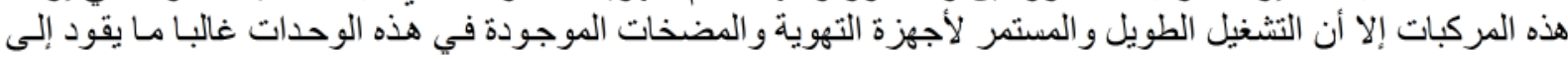

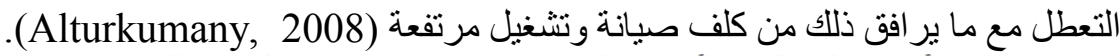

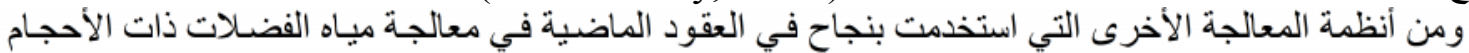

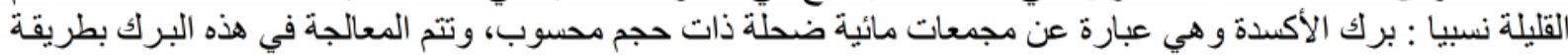

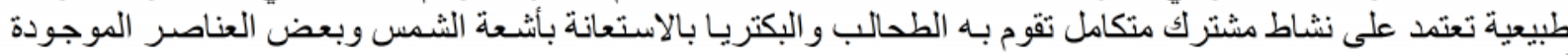
أصلا في مياه الفضلات. تصنئ.

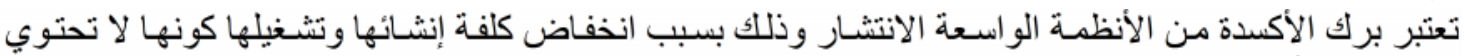

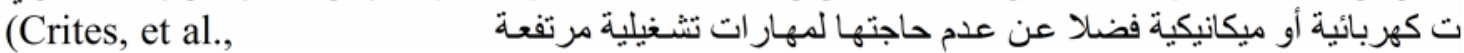

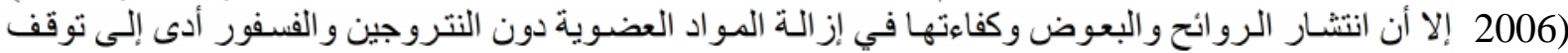

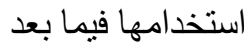

الوقت الحاضر ومع بروز تقنيات استخدام النباتات المائية الطافية (Mycrophyte)

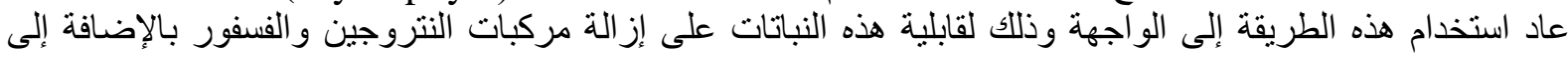

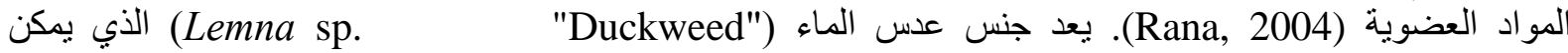

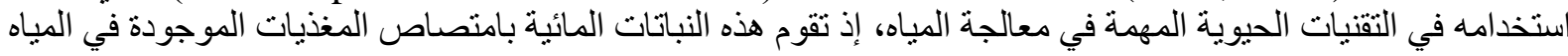

وتحويلها إلى كتلة حية تستخدم في تغذيةً الحيو انات و الإنسان (Leng , et. al, 1994) (Skillicorn, et. al, 1993)

(Phuc, et. al, 2001) (Hanczakowski, et. Al, 1995)

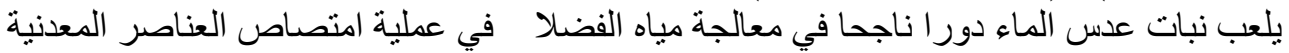

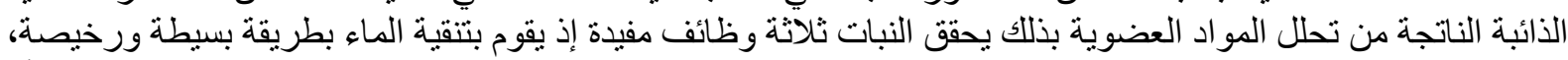

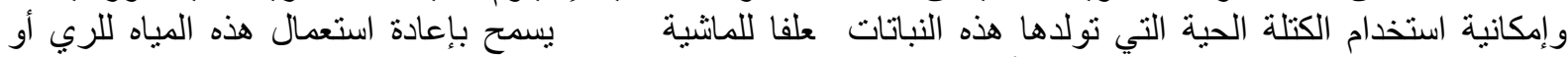

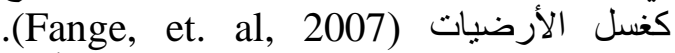

"Fronds" (Lemanceae)

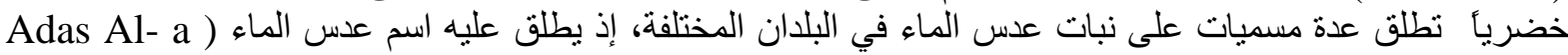

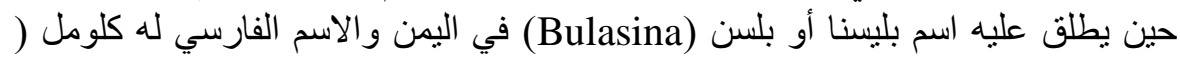

(ma

(Townsend, et . al, 1985) (Gelumel

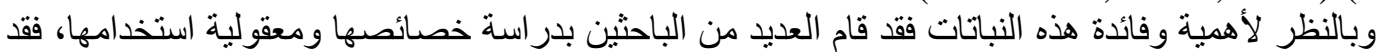

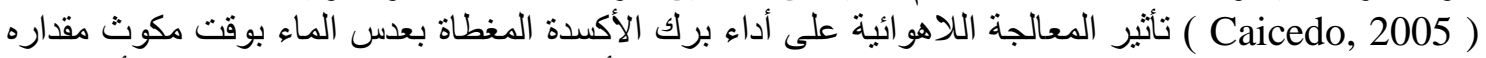

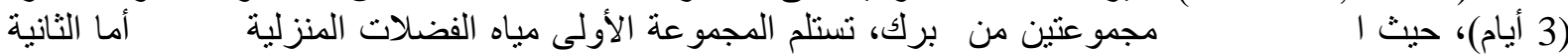

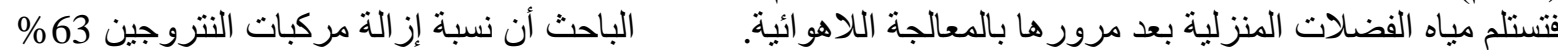

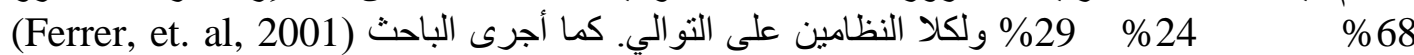

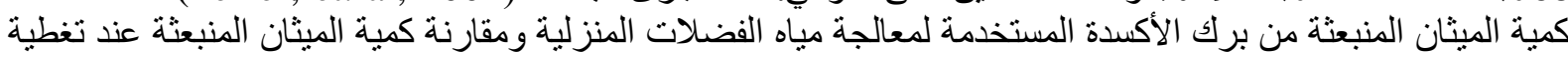
عدس الماء لسطح بركة وتغطية سطح بركة أخرى بالطحالب، حيث استتنج الباحث أن كمية الميثان المنبعثة كانت بمعدل 


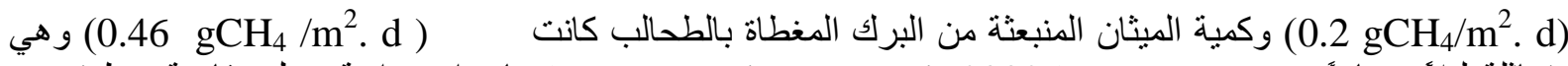

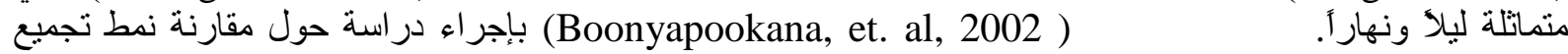

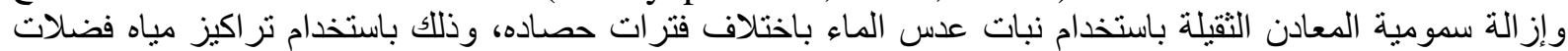
مختلفة مقدار ها (إلة

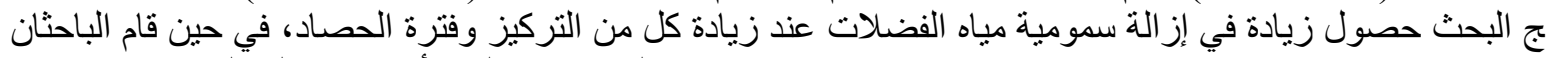

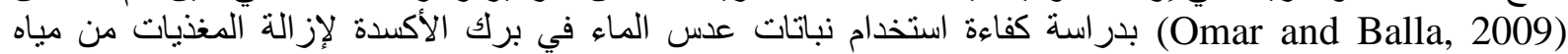

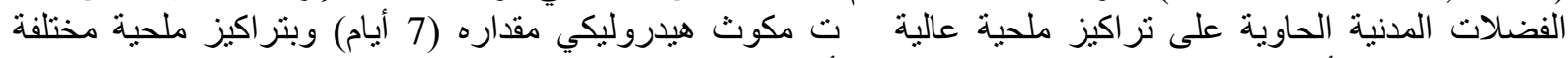

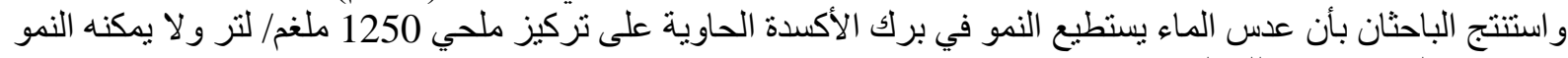

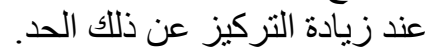
مع تلاك غير الحاوية (Duckweed)

يهدف هذا البحث إيجاد تأثثير تغيير الأحمال العضوية وأحمال النتروجين والفسفور في المو اد العضوية و النتروجين والبه والفيفور عليه التي تعمل تحت الظروف التشغيلية نفسها.

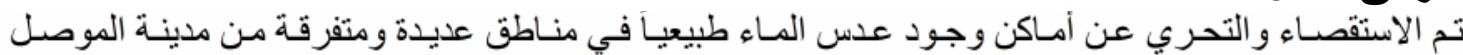

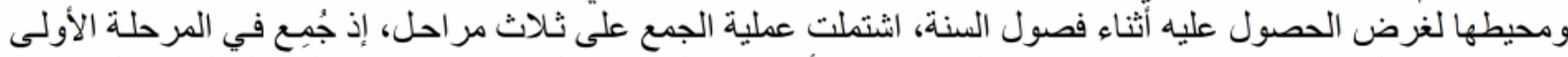

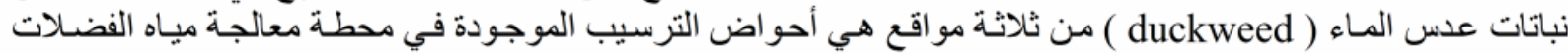

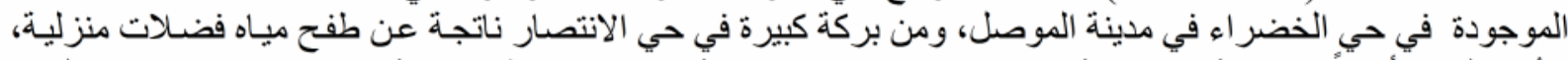

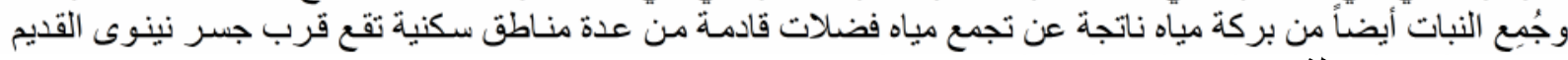
في نهر دجلة.

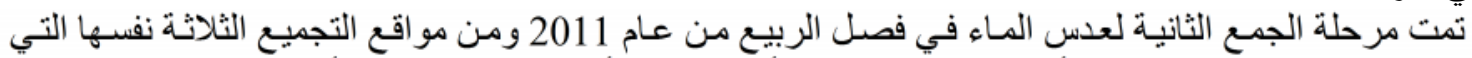

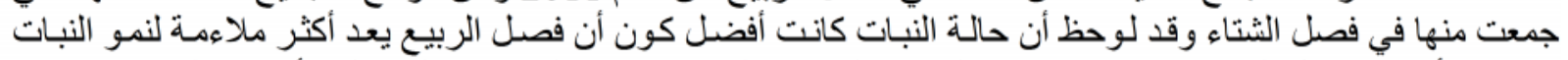

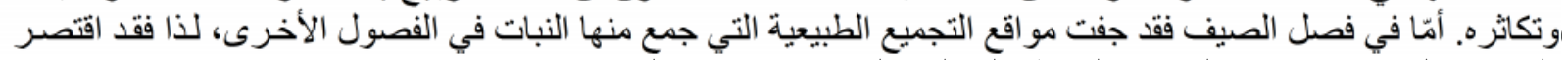

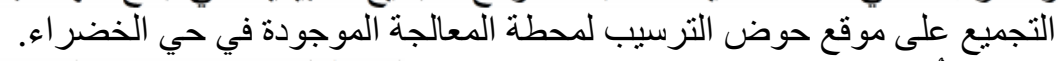

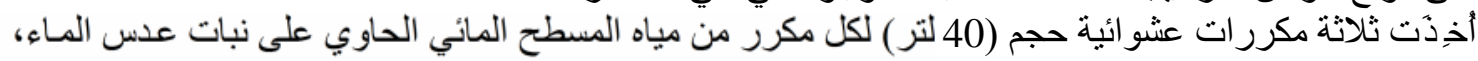

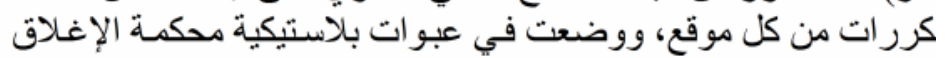
اختيرت ثلاثة

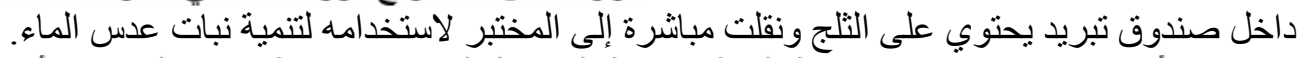

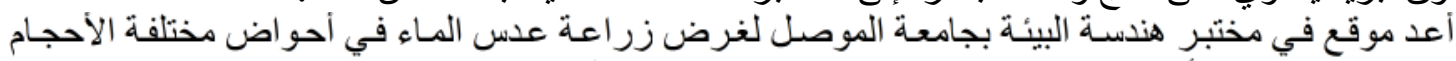

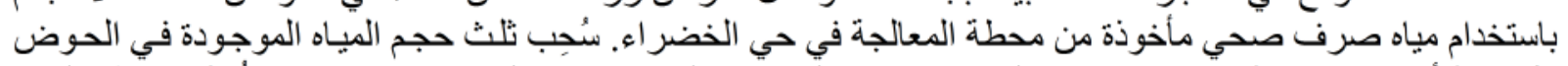

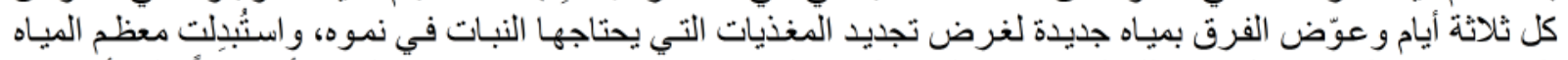

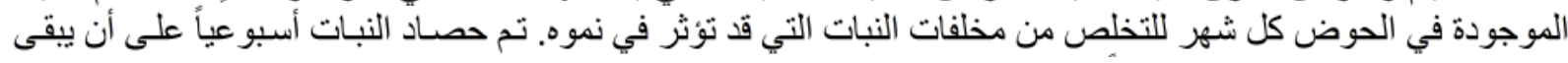

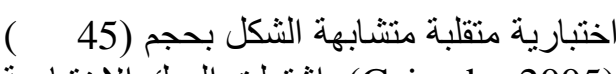

$\% 25$

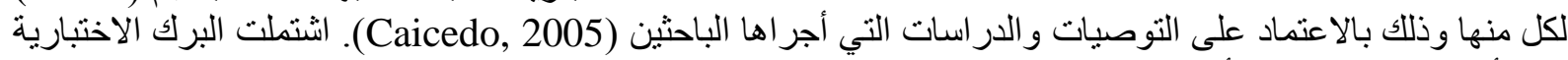

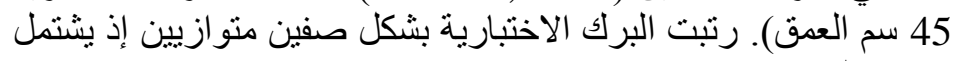

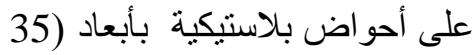

إذ تعمل على تنظيم النمو و العمليات الحيوية كل صف على ثماني برك مرنبة على بادئ التو الي مع بعضها البعض. 1986 مهر

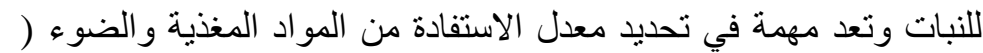

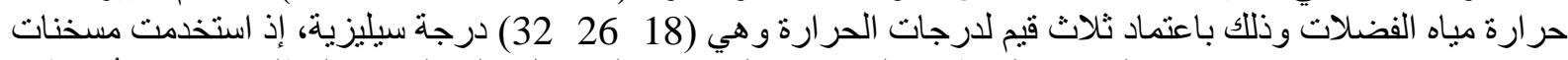

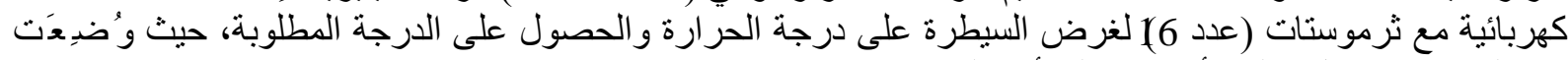

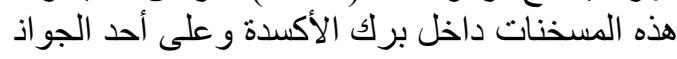

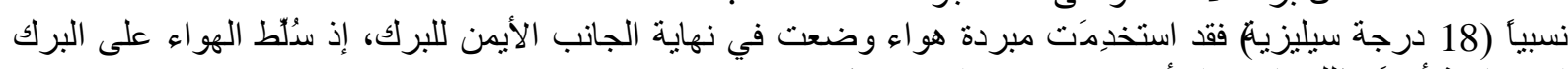

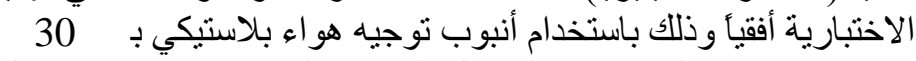

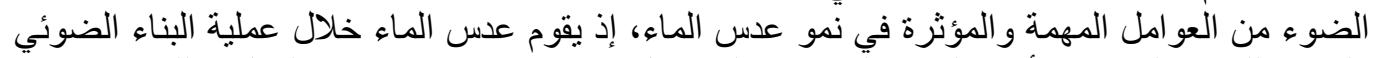

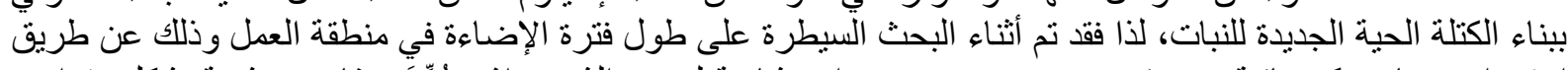

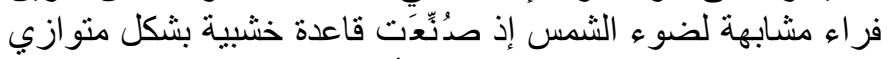

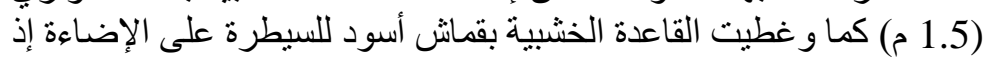

استخدام مصابيح كهربائية عدد ( 9 ( ( 2) (5) 


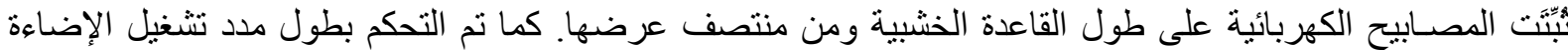

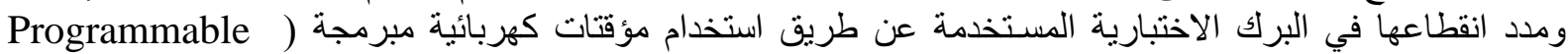

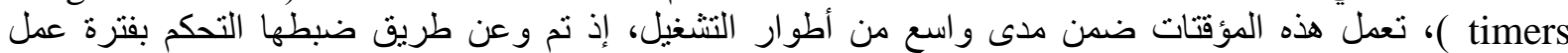
6
18)
6

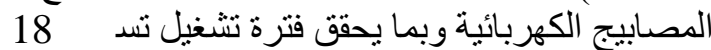

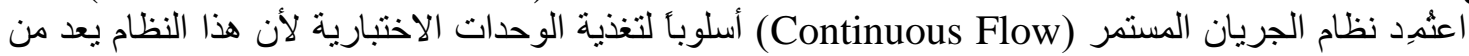

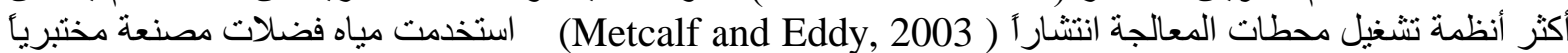

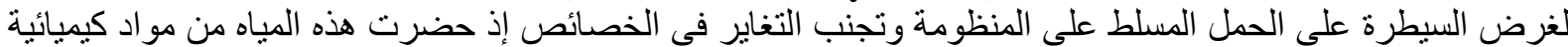

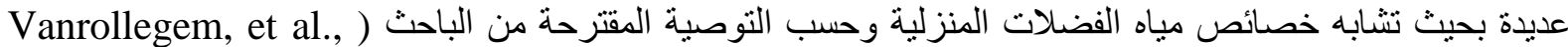

2001) وكما مبين في الجدول ابهن (1).

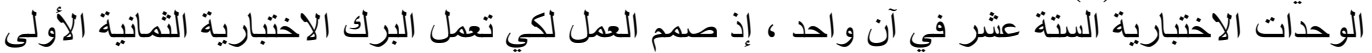

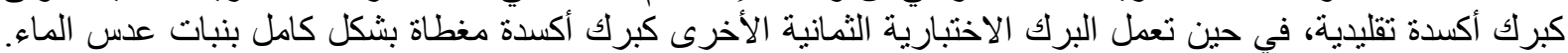

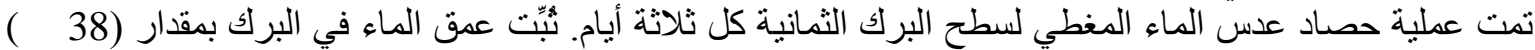
كل بركة وحسب التوصية المقترحة من الباحث (Caicedo, 2005). ولغرض تحقيق أهداف البحث ودراسة النظام

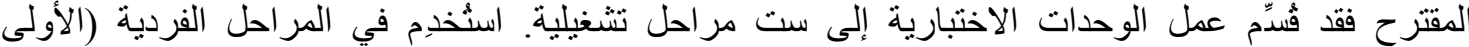

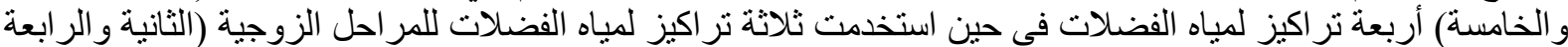

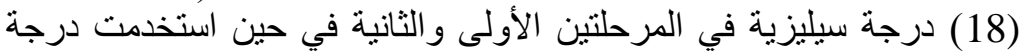

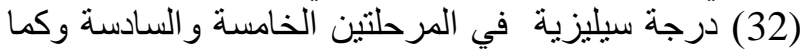

تم تغيير وقت المكوث الهيدروليكي (Hydraulic Detention Time, HDT) في البحث في حين استخدم وقت مكوث هيدروليكي ثابت في كل بركتين إحداهما المغطاة بنبات عدس الماء والأخرى غير المغطاة وذللك للمقارنة في كفاءة

(3) يبين خصائص المر احل التشغيلية الستة لعمل المنظومات الاختبارية الخاصة بالبراة البحث.

جدول رقم ( 1 ): المواد المستخدمة في تصنيع مياه الفضلات المستخدمة في البحث

\begin{tabular}{|c|c|c|}
\hline الرمز الكيميائي & اسم المادة & التسلسل \\
\hline $\mathrm{NH}_{4} \mathrm{CL}$ & كلوريد الأمونيوم & 1 \\
\hline- & بييتون & 2 \\
\hline $\mathrm{KH}_{2} \mathrm{PO}_{4}$ & فوسفات البوتاسيو ثثائية الهيدروجين & 3 \\
\hline $\mathrm{C}_{6} \mathrm{H}_{12} \mathrm{O}_{6}$ & & 4 \\
\hline- & الحليب & 5 \\
\hline $\mathrm{K}_{2} \mathrm{HPO}_{4}$ & Orthophosphate Anhydrous & 6 \\
\hline $\mathrm{MgSO}_{4} \cdot 7 \mathrm{H}_{2} \mathrm{O}$ & كبريتات المغنيسيوم & 7 \\
\hline $\mathrm{CH}_{4} \mathrm{~N}_{20}$ & يوريا ( DIDACTIC) & 8 \\
\hline
\end{tabular}

الجدول روم (2) : تراكيز مياه الهضلات المستخدمه في المراحل التتعيليه السته

\begin{tabular}{|c|c|c|c|}
\hline \multicolumn{4}{|c|}{ المراحل التثغيلية (الأولى ، الثالثة والخامسة) } \\
\hline TP (mg/l) & TN (mg/l) & COD (mg/l) & 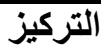 \\
\hline 8 & 40 & 500 & \\
\hline 9 & 45 & 500 & \\
\hline 15 & 75 & 500 & \\
\hline 16 & 80 & 500 & \\
\hline \multicolumn{4}{|c|}{ المراحل التشغيلية (الثانية ، الرابعة و السادسة) } \\
\hline TP (mg/l) & TN (mg/l) & COD (mg/l) & التركيز \\
\hline 10 & 50 & 500 & \\
\hline 12 & 60 & 500 & \\
\hline 20 & 100 & 500 & \\
\hline
\end{tabular}


جدول رقم (3) :خصائص المراحل التشغيلية لعمل الوحدات الاختبارية الخاصة بالبحث

\begin{tabular}{|c|c|c|c|c|c|c|c|c|c|c|c|c|c|c|c|c|c|}
\hline \multicolumn{8}{|c|}{ برك الأكسدة (مغطاة بعدس الماء) } & \multicolumn{8}{|c|}{ برك الأكسدة (بدون تغطية بعدس الماء) } & \multirow{2}{*}{ 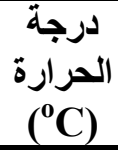 } & \multirow{2}{*}{ التثغيلية } \\
\hline \multicolumn{8}{|c|}{ وقت التعويق (يوم) } & \multicolumn{8}{|c|}{ وقت التعويق (يوم) } & & \\
\hline 9 & 15 & 9 & 12 & 6 & 15 & 12 & 6 & 9 & 15 & 9 & 12 & 6 & 15 & 12 & 6 & 18 & \\
\hline 9 & 15 & 12 & 9 & 15 & 12 & 9 & 6 & 9 & 15 & 12 & 9 & 15 & 12 & 9 & 6 & 18 & الثانية \\
\hline 9 & 15 & 9 & 12 & 6 & 15 & 12 & 6 & 9 & 15 & 9 & 12 & 6 & 15 & 12 & 6 & 26 & \\
\hline 9 & 15 & 12 & 9 & 15 & 12 & 9 & 6 & 9 & 15 & 12 & 9 & 15 & 12 & 9 & 6 & 26 & \\
\hline 9 & 15 & 9 & 12 & 6 & 15 & 12 & 6 & 9 & 15 & 9 & 12 & 6 & 15 & 12 & 6 & 32 & \\
\hline 9 & 15 & 12 & 9 & 15 & 12 & 9 & 6 & 9 & 15 & 12 & 9 & 15 & 12 & 9 & 6 & 32 & \\
\hline
\end{tabular}

النتائج و المناقثشة

1. تأثنير تغير الأحمال النتروجينية المسلطة في الوحدات الاختبارية في كفاءة إز الة الأمونيا

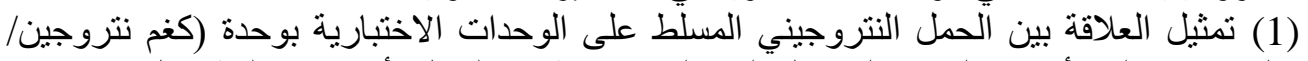

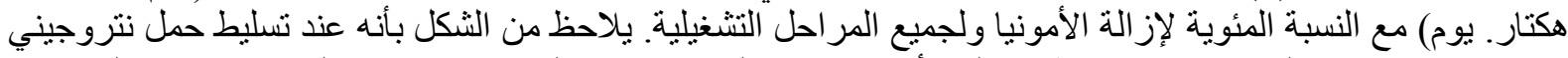

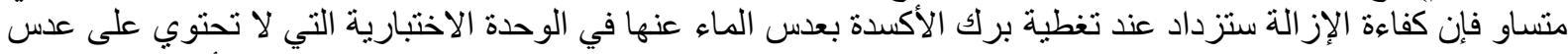

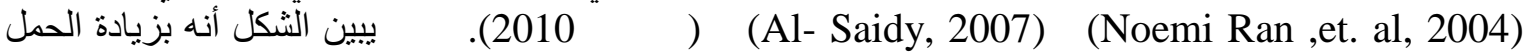

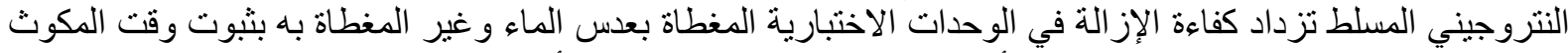

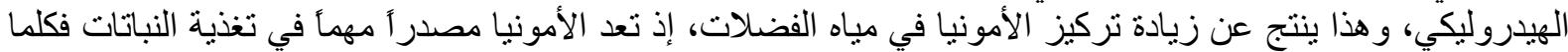

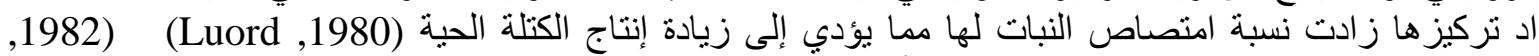

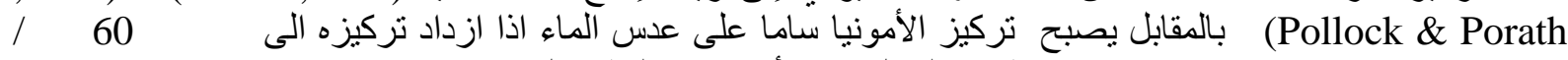

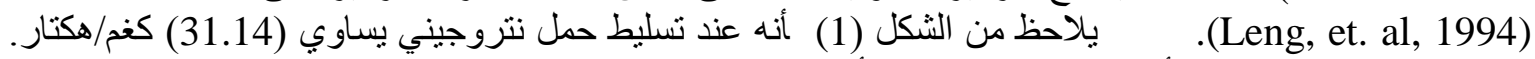

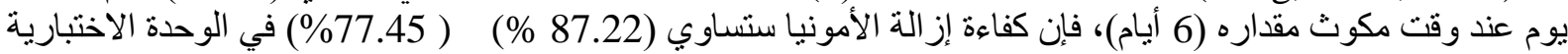
المغطاة بعدس الماء وغير المغطاة به على التو الي.

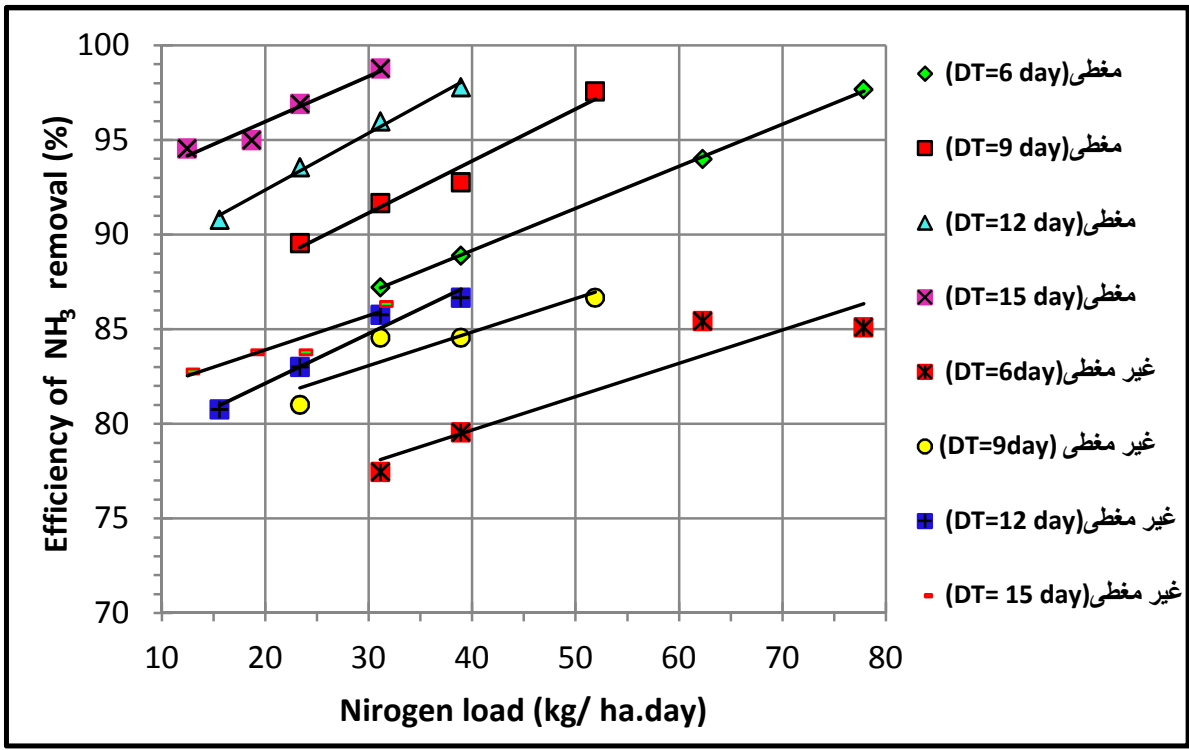

التتكل (1): العلافه بين الحمل النتروجيني المسلط على الوحدات الاختباريه وكهاءه إزاله الامونيا (NH3)

2. تأثير تغير الأحمال النتروجينية المسلطة في الوحدات الاختبارية في كفاعة إزالة النترات(NO3) (NO) والنتريت (NO)

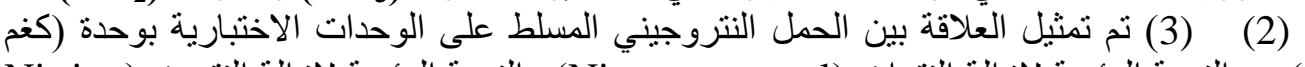

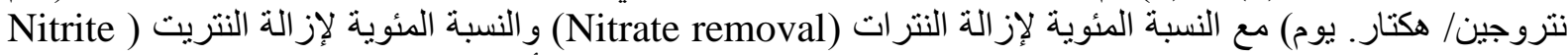
(removal 
كفاءة الإزالة ستزداد عند تغطية برك الأكسدة بعدس الماء عنها في الوحدة الاختبارية التي لا تحتوي على عدس ماء ، (Zimmo, et. al, 2000) (Noemi Ran, et. al, 2004)

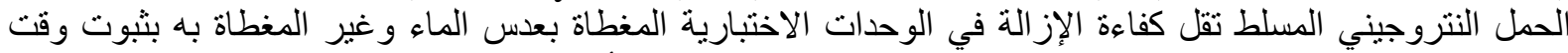

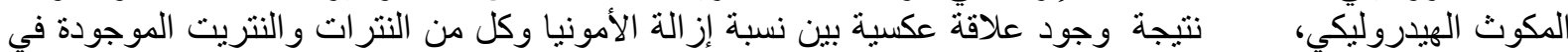

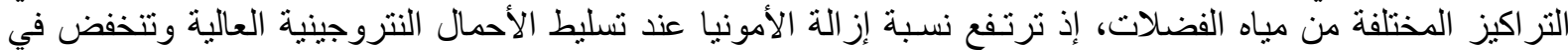

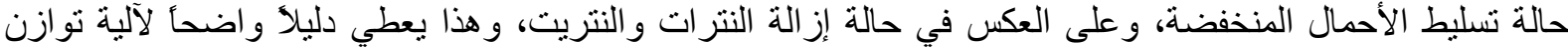

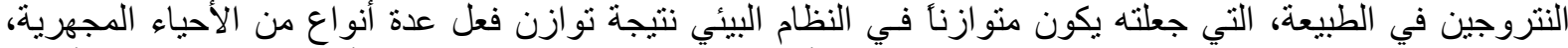

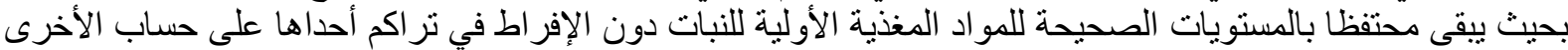
.). (1984

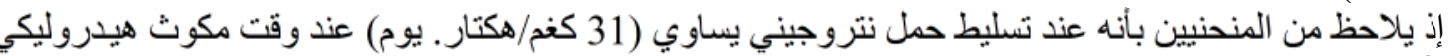

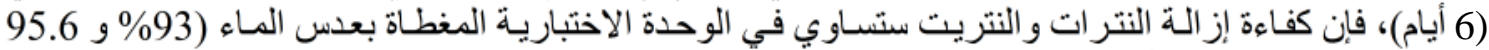

\%)، في حين ستكون في برك الأكسدة غير المغطاة به (83.2\% 87.2 \%

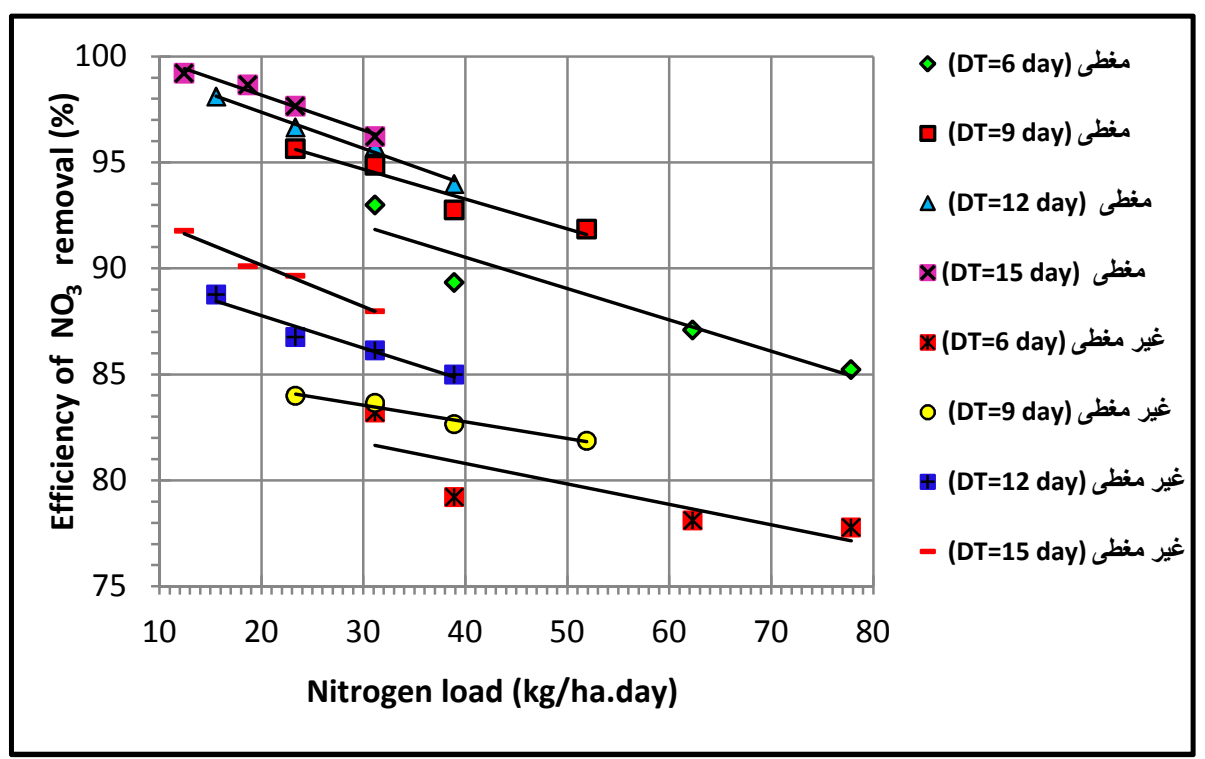

الثكل (3) : العلاقة بين الحمل النتروجيني المسلط على الوحدات الاختبارية وكفاءة إزالة النترات (NO3)

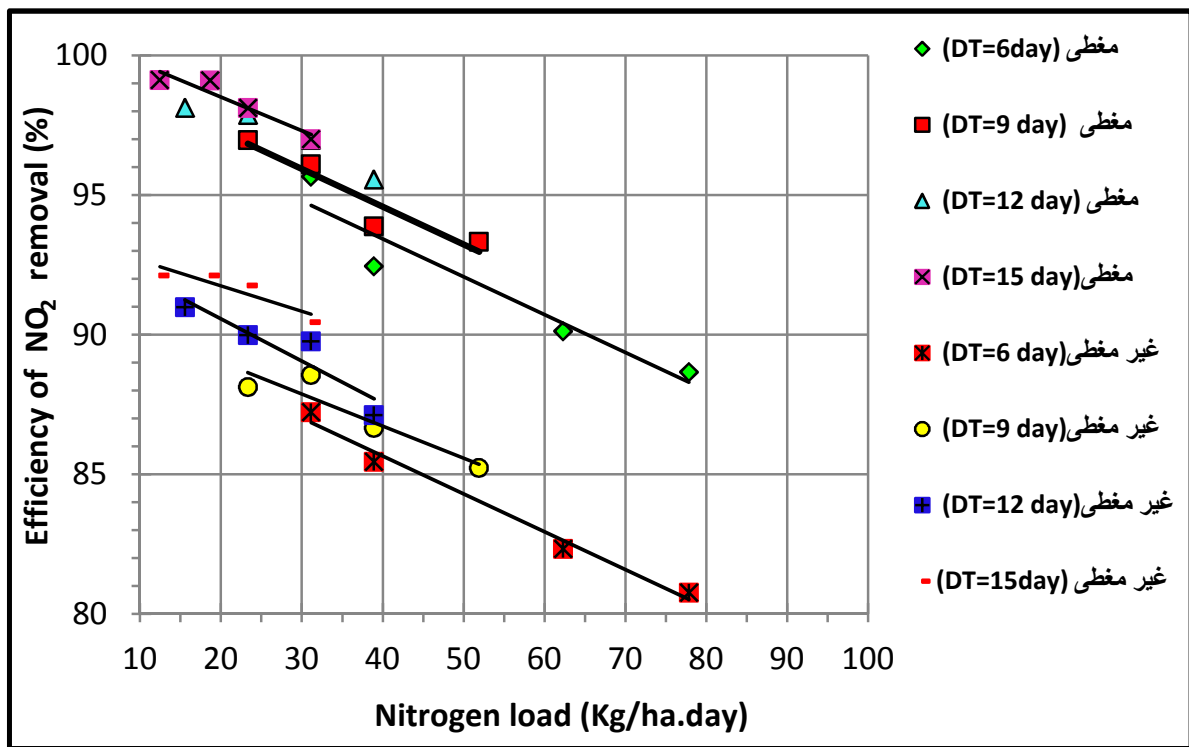

الثكل (2) : العلاقة بين الحمل النتروجيني المسلط على الوحدات الاختبارية وكفاءة إزالة النتريت (NO2) 
3. تأثير تغير أحمال الفسفور المسلطة في الوحدات الاختبارية في كفاءة إزالة الفوسفات (PO)

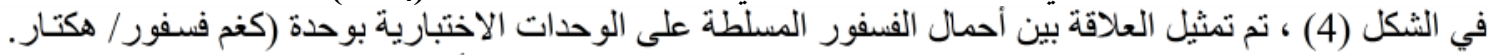

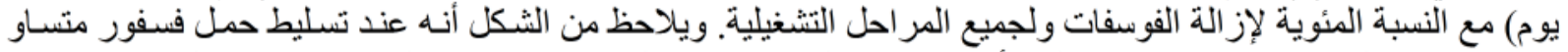

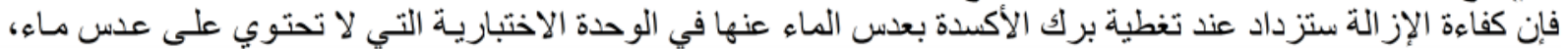

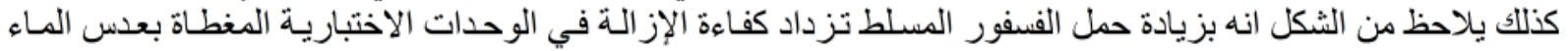

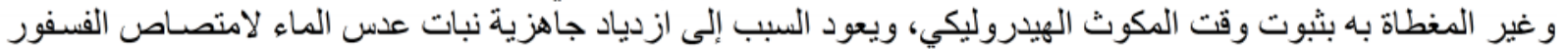

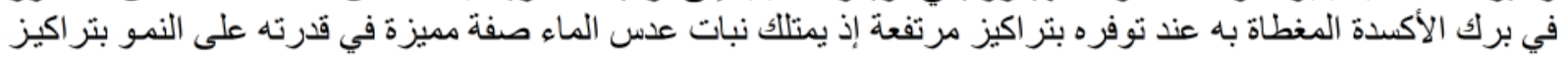

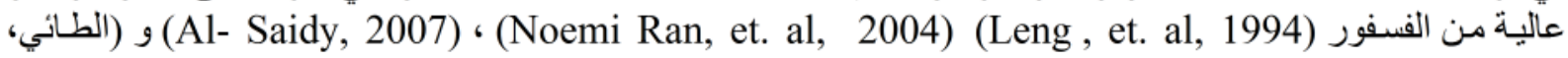

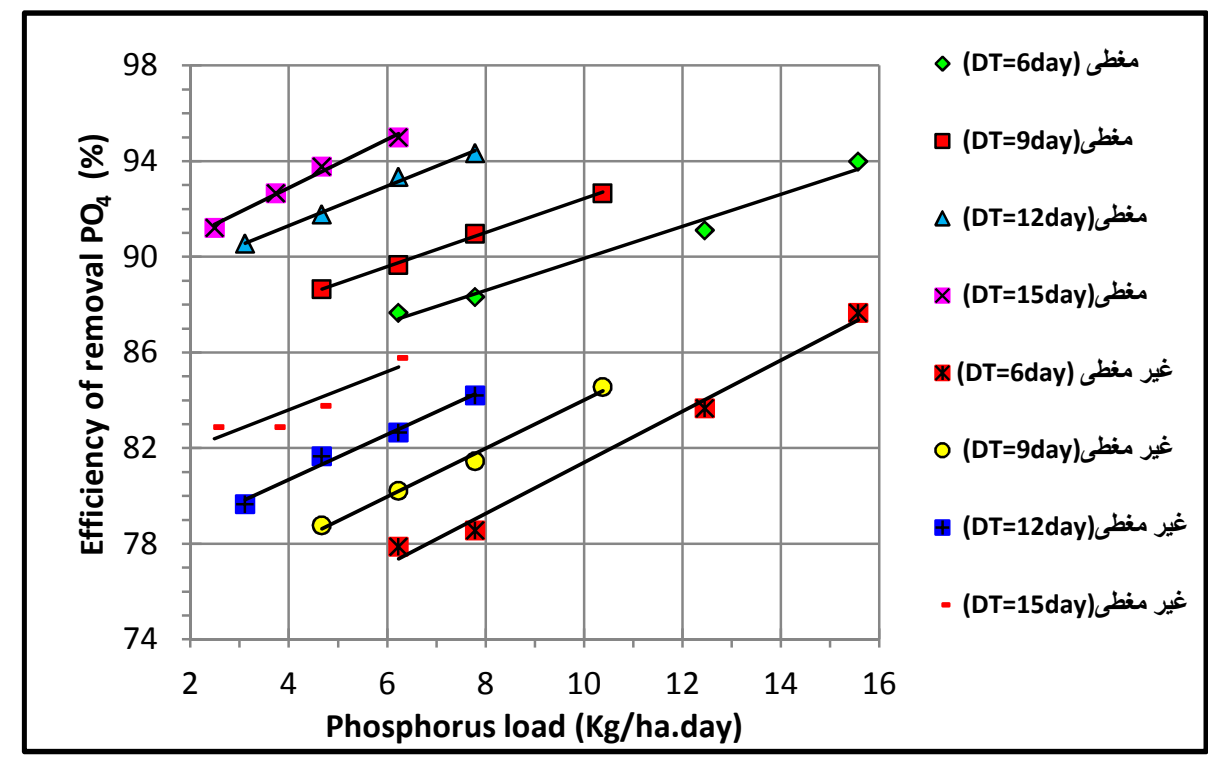

الثكل (4) : العلاقة بين أحمال الفففور المسلطة على الوحدات الاختبارية وكفاءة إزالة الفوسفات (PO4)

4. تأثير تغيير الأحمال العضوية المسلطة في الوحدات الإختبارية في كفاعة إزالة المواد العضوية العادية

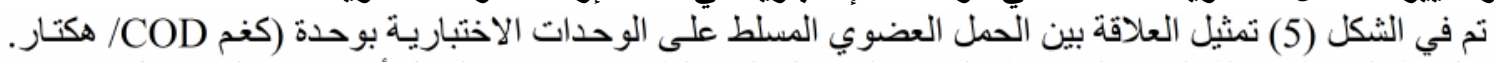

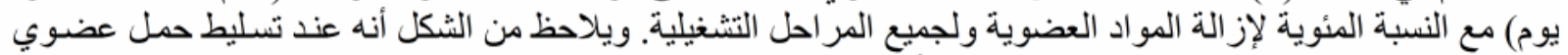

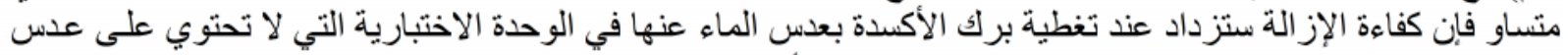

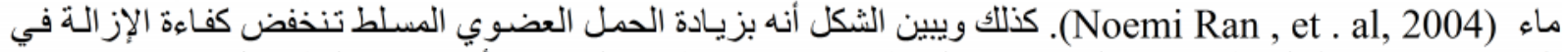

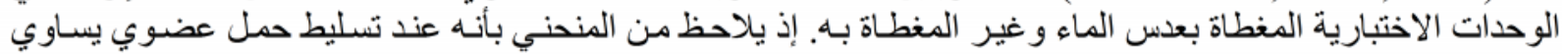

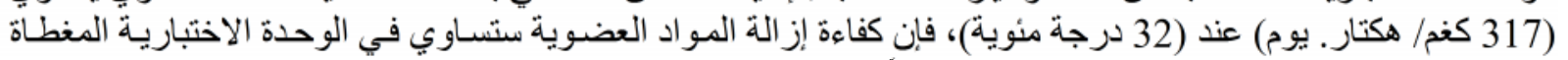

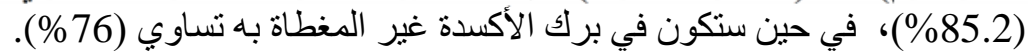

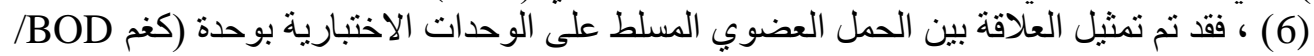

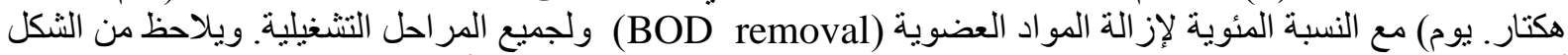

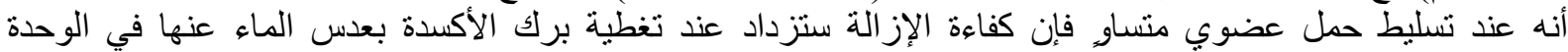

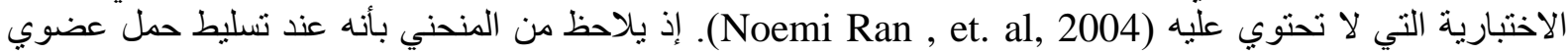

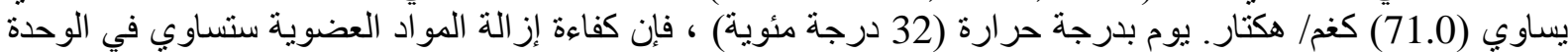
الاختبارية المغطاة بعدس الماء (71) (93.34)، في حين ستكون في برك الأكسدة غير المغطاة به تساوي (88.632\%). 


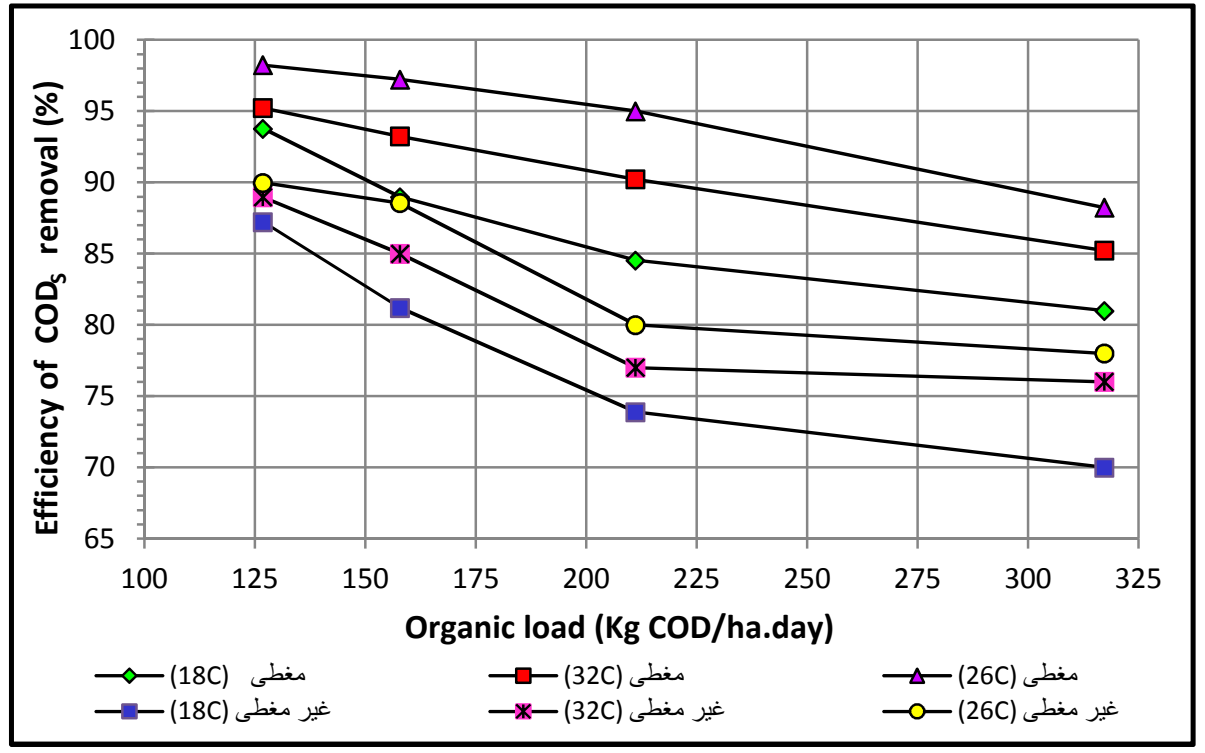

الثكل (5) : العلاقة بين الحمل العضوي المسلط على الوحدات الاختبارية وكفاءة إزالة المواد العضوية المذابة $\left(\mathrm{COD}_{\mathrm{S}}\right)$

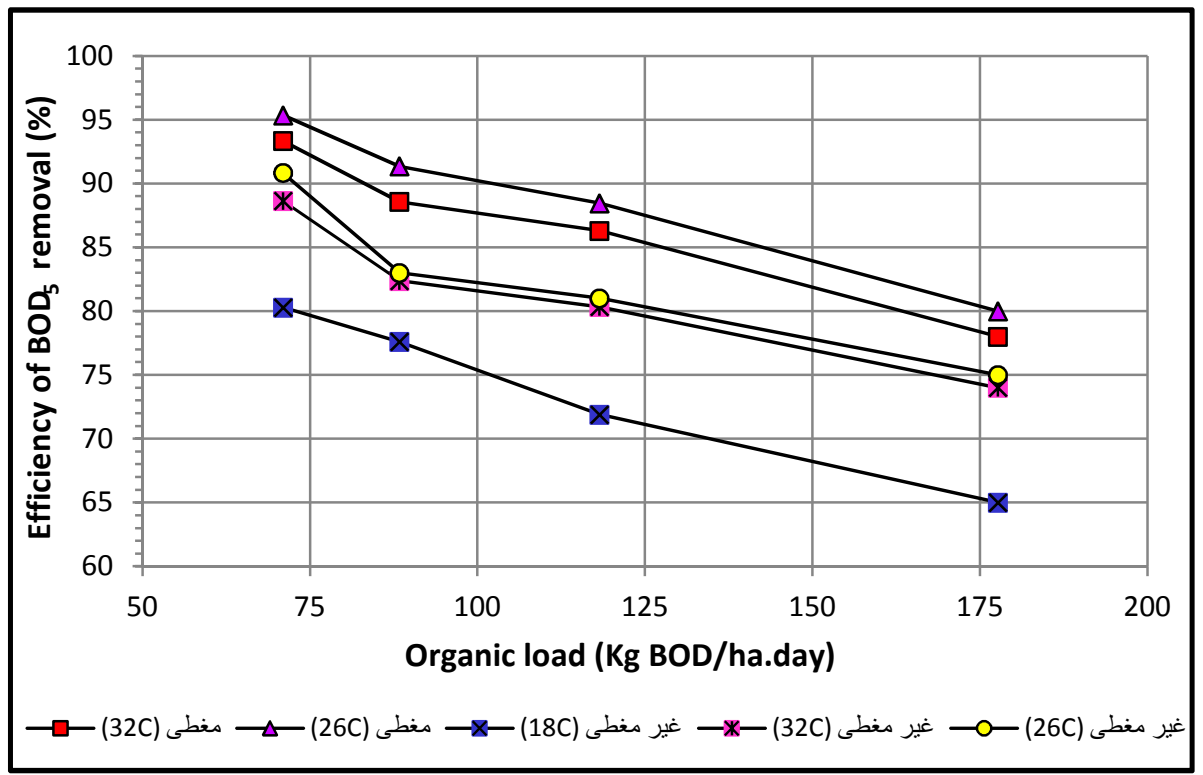

المشكل (6): العلافه بين الحمل العضوي المسلط على الوحدات الاختباريه وكهاءة إزاله المواد العضويه $\left(\mathrm{BOD}_{5}\right)$

| - الاستتناجات

1. يساهم نبات عدس الماء بتحسين كفاءة إز الة كل من المواد العضوية والمغذيات (NH $\% 77.45 \% 83.22 \quad \% 75 \quad \% 78)$

\% \% \% \% \% \% \% \% \% $\left(\mathrm{PO}_{4} \mathrm{NH}_{3}, \mathrm{NO}_{2}, \mathrm{NO}_{3}, \mathrm{BOD}_{5}, \mathrm{COD}\right)$

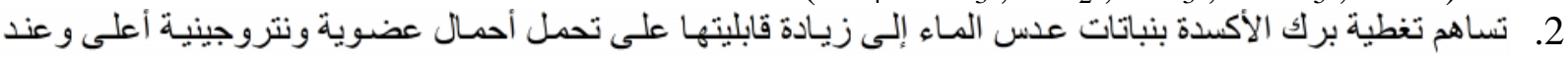

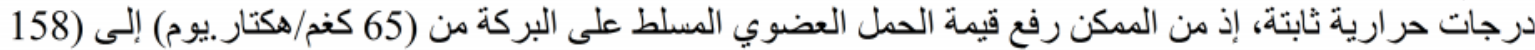

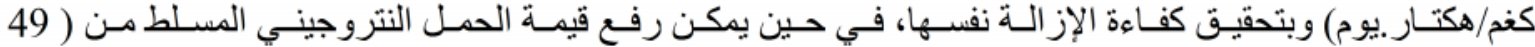
كغم/هكتار .يوم) إلى (111 كغم/هكتار ييوم) و تحقيق نسبة الإز الة نفسها. 


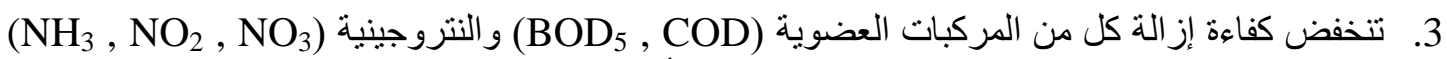

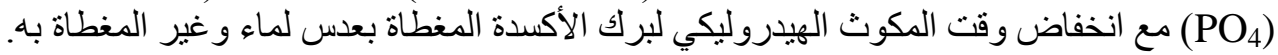

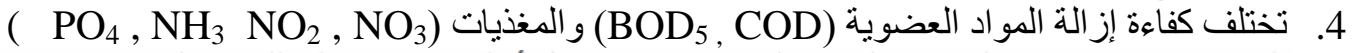

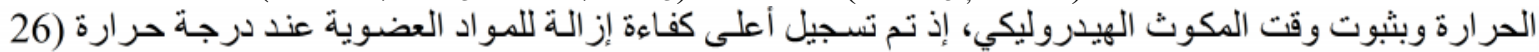

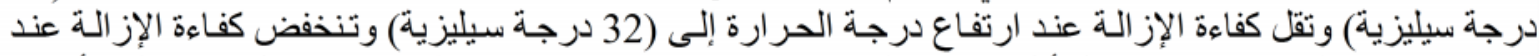

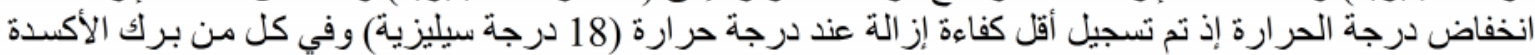

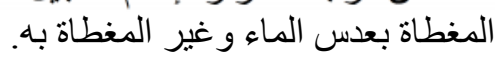

5. تنخفض كفاءة إزالة كل من النترات والنير النتريت (NO

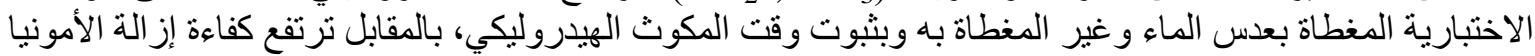

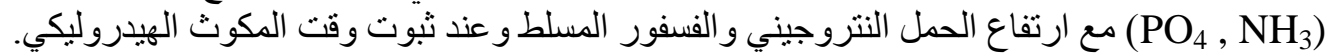
6. تختلف كفاءة إز الة المو اد العضوية (POD

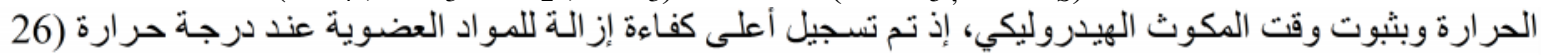

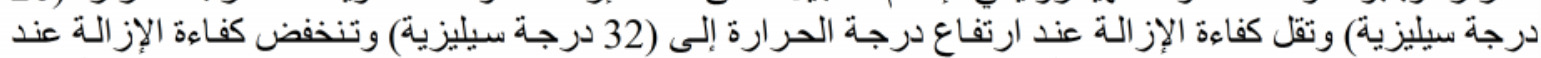

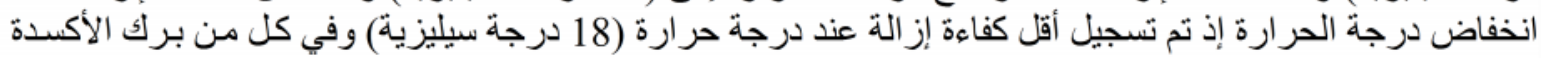
المغطاة بعدس الماء و غير المغطاة بهاء.

السعدي، حسين علي؛ الدهام ، نجم قمر و الحصان، ليث عبد الجليل (1986)، "علم البيئة المائيسة"، وزارة التعليم العـالي .538 - 421 :

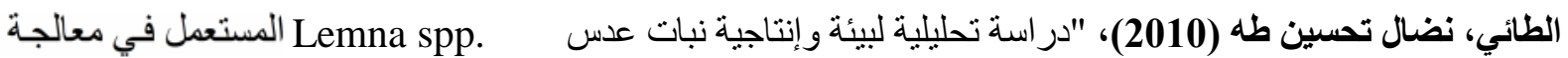

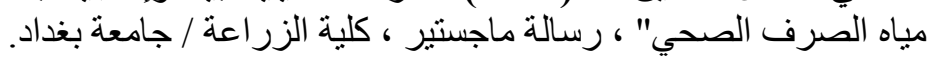
لثروة السمكية"، وزارة التعليم العالي والبحث العلمي، جامعة البصرة. البعة العراق، الناصري، سفيان كامل (1988)، " .231:

شارلس ، ساوثويك ، ترجمة صالح، قيصر نجيب؛ الدباغ، سهيلة عباس أحمد وصالح، طارق محمد (1984)، "علم البيئة ونو عية بيئتنا"، طبع جامعة الموصل، رقم الأيداع في المكتبة الوطنية مولود، بهرام خضر؛ السعدي، حسين علي و الأعظمي، حسين أحمد شريف (1991)، "علم البيئة و التلوث"، كلية التربية 366 :

AL-Saidy, R . A . J. (2007), "The treatment of domestic wastewater using duckweed plant" ,M. Sc. thesis, University of Baghdad, pp 31-44.

Alturkumany, A. M. S. (2008), "Assess the current status of small treatment plants in syria", Syria,Ch3, pp 1-46.

Boonyapookana, B. , Upatham, E. S, Kruatrachue, M. ,Pokethitiyook, P and Singhakaew, S. (2002), "Phytoaccumulation and phytotoxicity of cadmium and chromium in duckweed Wolffia globosa" International Journal Phytoremediation, Vol. 4, No. 2, pp 87100.

Caicedo Bejarano, J. R. (2005), "Effect Of Operational Variables on Nitrogen Transformations In Duckweed Stabilization Ponds", Ph.D thesis, University of Wageningen, pp 1-10.

Crites, R., Middlebrooks, E., Reed, S., 2006,"Natural Wastewater Treatment Systems", New York, Ch1, pp 1-10.

Fange yy,babourina o, rengelz, yangxi, pupm. Et. Al (2007), "Ammonina and nitrate uptake by the floating plant", landoltia punclate ann bot 99, pp 365-370. 
Ferrer, A. V. M and Van Der Steen, N. P And Samarasinghe, K. G; Gijzen, H.J (2001) "Quantification and comparison of methane emissions from algae and duckweed - based wastewater treatment ponds" Universidad del valle / instituto cinara, pp 92-98.

GESAMP (1993), "Impact of Oil and Related Chemical and Wastes on the Marine Environment". R. Stud. GESAMP. 50:180-181.

Hanczakowski, P.; Symczyk, B. and Wawrzyski, M. (1995), "Composition and nutritive value of sewage-grown duckweed (Lemna minor) for rats Animal". Feed Science Technology. 52: 339-343.

Kadlec, R. and Knight, R. (1996), "Treatment Wetland", S. Boca Raton, Florida: CRC Press, Inc.

Kadlec, R. H. (1999), "the limits of phosphorus removal in wetlands . Wetlands Ecology And Managaneze. Vol 3, pp 165-175.

Leng, R.A.; Stambolie, J.H. and Bell, R.E. (1994), "Duckweed a potential high protein feed resource for domestic animals and fish In: Improving animal production systems based on local feed resources. 7th AAAP Animal Science Congress". pp: 100-117.Livestock Research for Rural Development. 7 (1). pp:36-106. (Centre for Duckweed Research \& Development University of New England Armidale, NSW 2351).

Leng, R.A.; Stambolie, J.H. and Bell, R.E. (1994), "Duckweed a potential high protein feed resource for domestic animals and fish In: Improving animal production systems based on local feed resources. 7th AAAP Animal Science Congress. pp: 100-117.Livestock Research for Rural Development", 7 (1). pp:36-106. (Centre for Duckweed Research \& Development University of New England Armidale, NSW 2351).

Luord, A. (1980), "Effects of nitrogen and phosphorus upon the growth of some Lemnaceae. In:Biosystematische Untersuchungen in der Familie der Wasserlinsen (Lemnaceae),Veroffentlichungen des Geobotanischen Institutes der ETH Zurich", Landolt E. Band 70.

Metcalf and Eddy, Inc. (2003), "waste water engineering treatment/disposal/reuse", fourth edition, McGraw-Hill, inc, New York, Ch8, pp 661-665.

Noemi R. and Moshe, A. ,Gideon, O. (2004) ",A pilot study of constructed wetlands using duckweed (Lemna gibba L.) for treatment of domestic primary effluent in Israel", Water Research Vol. 38 , pp 2241-2248.

Omar, M. and Balla, D. (2009) "Drainage water purification in saline detention ponds with duckweeds" Progress in Managing Water for Food and Rural Development, VOL. 48, pp1724.

Phuc, B. H. N.; Lindberg, J. E.; Ogle, B. and Thomke, S. (2001), "Determination of the nutritive value of tropical biomass products as dietary ingredients for monogastrics using rats: 1. comparison of eight forage species at two levels of inclusion in relation to a casein diet", Asian-Aust. Journal Animal Science14(7): 986-993.

Porath, D. and Pollock, J. (1982), "Ammonia stripping by duckweed and its feasibility in circulating aquaculture". Aquat. Bot. 13: 125-131.

Rana, S., (2004), "Topological Data Structures for Surfaces: An introduction to geographical information science", John Wiley \& Sons, Chichester. 
Skillicorn, P.; Spira, W. and Journey, W. (1993), "Duckweed aquaculture - a new aquatic farming system for developing countries". The World Bank. Washington DC. pp:76.

Skillicorn, P.; Spira, W. and Journey, W. (1993), "Duckweed aquaculture - a new aquatic farming system for developing countries", The World Bank. Washington DC. pp:76.

Thurman, H. V. and Webber. G. (1984), Marine biology, Charles E. Merrll Publ. Comp. Collumbus, Ohio.

Townsend, C. C., Guest, Evan, Omar,S. A., And Al-Khayat.A. H. (1985) "Flora of Iraq". Volume eight (monocotyledons), Ministry of agriculture \& agrarian reform, Iraq. pp: 36-37.

Vanrolleghem, P. A. , Nopens, I. and Capalozza, C. (2001), " Stability analysis of a synthetic municipal wastewater", Department Of Applied Mathematics, Biometrics and Process Control.

Yakovlev, V. and Serobaba, I.I. (1994), "International integration of environment protection measures with regard for national priorities as the basis for black sea ecosystem sustainable development". Tr. Yugnire. Proc. South. Sci. Res. Inst. Mar. Fish Ocean. 41: 15-18.

Zimmo O. R and Al Sa'ed; Gijzen R. H (2000), "Comparison between algae-based and duckweed-based wastewater treatment: differences in environmenta conditions and nitrogen transformations", Water Science and Technology, Vol. 42, No. 11, pp 215-222.

تم اجراء البحث في كلية ألهندسة = جامعة ألموصل 